INSERM U491, Faculté de Médecine, 27 Bd Jean Moulin, 13385 Marseille Cedex 5, France

L Villard

N Lévy

A Kpebe

C E Schwartz

$M$ Fontès

Département de Génétique Médicale, Laboratoire de Génétique

Moléculaire, Hôpital

d'Enfants de la

Timone, 13385

Marseille Cedex 5,

France

N Lévy

V Labelle

Department of Clinical Neuroscience and

Molecular Medicine,

Karolinska Hospital,

SE-171 76 Stockholm,

Sweden

F Xiang

Z Zhang

M Anvret

INSERM U399, Faculté de Médecine, 27 Bd Jean Moulin, 13385 Marseille Cedex 5,

France

C Chevillard

Department of Molecular Sciences, AstraZeneca R\&D, Södertälje, SE-151 85 Södertälje, Sweden

Z Zhang

M Anvret

Greenwood Genetic Center, Greenwood, South Carolina 29646, USA

C E Schwartz

Service de Neurologie Pédiatrique, Hôpital du Kremlin Bicêtre,

Paris, France

M Tardieu

CRI INSERM 96012, Université Paris Sud, France

M Tardieu

INSERM U129, CHU Cochin-Port-Royal, 75014 Paris, France

J Chelly

Correspondence to $\mathrm{Dr}$ Fontès, Michel.Fontes@ medecine.univ-mrs.fr

Revised version received 29 March 2001

Accepted for publication 17 April 2001

\title{
Segregation of a totally skewed pattern of X chromosome inactivation in four familial cases of Rett syndrome without $M E C P 2$ mutation: implications for the disease
}

\author{
Laurent Villard, Nicolas Lévy, Fengqing Xiang, Arlette Kpebe, Véronique Labelle, \\ Christophe Chevillard, Zhiping Zhang, Charles E Schwartz, Marc Tardieu, Jamel Chelly, \\ Maria Anvret, Michel Fontès
}

\begin{abstract}
Background-Rett syndrome is a neurodevelopmental disorder affecting only girls; 99.5\% of Rett syndrome cases are sporadic, although several familial cases have been reported. Mutations in the $M E C P 2$ gene were identified in approximately $70-80 \%$ of sporadic Rett syndrome cases.

Methods-We have screened the MECP2 gene coding region for mutations in five familial cases of Rett syndrome and studied the patterns of $\mathrm{X}$ chromosome inactivation (XCI) in each girl.

Results-We found a mutation in MECP2 in only one family. In the four families without mutation in $M E C P 2$, we found that (1) all mothers exhibit a totally skewed pattern of XCI; (2) six out of eight affected girls also have a totally skewed pattern of XCI; and (3) it is the paternally inherited $\mathbf{X}$ chromosome which is active in the patients with a skewed pattern of XCI. Given that the skewing of XCI is inherited in our families, we genotyped the whole $X$ chromosome using 32 polymorphic markers and we show that a locus potentially responsible for the skewed XCI in these families could be located on the short arm of the $\mathbf{X}$ chromosome.

Conclusion-These data led us to propose a model for familial Rett syndrome transmission in which two traits are inherited, an $X$ linked locus abnormally escaping $X$ chromosome inactivation and the presence of a skewed XCI in carrier women. (f Med Genet 2001;38:435-442)
\end{abstract}

Keywords: Rett syndrome; skewed X chromosome inactivation; $\mathrm{X}$ chromosome; $M E C P 2$

Rett syndrome (RTT, MIM 312750) is a severe neurological disorder affecting exclusively females. ${ }^{1}$ Its prevalence is about 1 in 15000 live born females. Rett patients stop developing at about 1 year of age, and have a series of clinical signs indicative of a neurodevelopmental abnormality, including arrest of brain development, regression of acquired milestones, and behavioural troubles (stereotypic hand movements, autism). ${ }^{2}$ Most cases are sporadic $(99.5 \%)$, although a few families have been reported. This pattern of inheritance is unusual and was until recently of totally unknown origin, thus making RTT one of the most exciting challenges in medical genetics. Several hypotheses have been proposed regarding the mode of inheritance and the mechanism by which Rett syndrome occurs. Male lethality has been proposed, but there is an apparently normal sex ratio in RTT families and no excess of miscarriages has been observed. Uniparental disomy has also been proposed, but after examination of Rett chromosomes, this hypothesis was ruled out. The most interesting suggestion, proposed by Thomas, ${ }^{3}$ is that the Rett mutation is male specific and can thus only be transmitted to females.

Another approach to elucidating the molecular mechanisms underlying this syndrome was to take advantage of the familial cases, in order to link the RTT locus to a particular region of a given chromosome. The $\mathrm{X}$ chromosome was first explored and several studies have excluded all of the $\mathrm{X}$ chromosome except the telomeric region of the long arm. ${ }^{45}$ Using cumulative data and multipoint analysis, it was shown that a RTT locus was linked to the Xq28 region, with a lod score of $2.9 .^{6}$ For some families, it was shown that the mutation originated from the grandfather and was transmitted by unaffected carrier mothers. ${ }^{5}$

Mutations in the human methyl-CpG binding protein $2(M E C P 2)$ gene were identified in $70-80 \%$ of sporadic Rett syndrome cases. ${ }^{7-9} \mathrm{We}$ have thus screened the coding region of the MECP2 gene looking for mutations in five familial Rett syndrome cases and found a MECP2 mutation in only one, thus questioning the molecular basis of the Rett syndrome phenotype in the other four families.

One unusual observation in Rett syndrome familial cases is that carrier mothers transmit a pathological trait affecting only females and are not affected themselves, although the mutation possibly originates from their father's germline. One possible hypothesis for such reduced penetrance in carrier females would be the presence of a skewed pattern of X chromosome inactivation (XCI). Sirriani et $a l^{6}$ reported a single RTT family in which an obligate carrier female had a completely biased XCI pattern, while her affected daughter exhibited a random XCI pattern. We thus focused our attention on the four families in which no mutation in the MECP2 coding region was identified. We assessed the XCI patterns in these families 
using the polymorphism of the CAG repeat of the androgen receptor $(A R)$ gene (Xq12). Our results show that a totally skewed pattern of XCI segregates in the four families although it does not cosegregate with the disease. We genotyped the whole $\mathrm{X}$ chromosome in these families and we show that the only active $\mathrm{X}$ chromosome in the affected patients is the paternal X, although maternal transmission of RTT is likely to occur at least in one family. A potential controlling locus for this skewed XCI pattern could be located on the short arm of the $\mathrm{X}$ chromosome. These data led us to propose a model involving escape from normal inactivation of one (or several) X linked genes, and we ruled out $M E C P 2$ as being the gene potentially escaping $\mathrm{X}$ inactivation in the cases studied.

\section{Methods}

FAMILIES

Families 1, 2, 3, and 5 in our report correspond to cases 5, 6, 2, and 3 of Xiang et al. ${ }^{5}$ Families 1 and 3 were reported by Hagberg et al, ${ }^{10}$ family 2 was reported by Haenggeli et al, ${ }^{11}$ family 4 has not been reported previously, and family 5 was reported by Ellison et al. ${ }^{12}$ All affected girls fulfilled the international criteria for Rett syndrome diagnosis.

DNA SOURCES

DNA was extracted from lymphoblastoid cell lines according to standard procedures.

INACTIVATION STUDIES

Androgen receptor

Primers were designed in the (CAG)n flanking sequences of the androgen receptor (HUMARA) gene intron $1 .{ }^{13}$ Forward primer AR-P1 was 5' labelled (Fam) and the reverse primer AR-P2 was unlabelled. Primer sequences were: AR-P1: Fam 5' TCC AGA ATC TGT TCC AGA GCG TGC 3'; AR-P2: 5' GCT GTG AAG GTT GCT GTT CCT CAT 3'. A total of $400 \mathrm{ng}$ of DNA were digested by HpaII and ethanol precipitated. PCR reactions were performed with $100 \mathrm{ng}$ of DNA both on HpaII digested and undigested DNA for all subjects. Males in our study were also tested under the same conditions for the allele size at the $A R$ locus after PCR on undigested DNA. For these males, PCR reactions on HpaII digested DNA were also used as digestion quality control (no amplification product on HpaII digested DNA at the $A R$ locus). PCR conditions were as follows: $1 \times$ PCR buffer, 0.2 $\mathrm{mmol} / 1 \mathrm{dNTPs}, 1.25 \mathrm{mmol} / 1 \mathrm{Mg}++$, and $0.5 \mathrm{U}$ Taq (Gibco BRL) in a $20 \mu \mathrm{l}$ final volume. Annealing temperature was $60^{\circ} \mathrm{C}$ for 30 cycles.

\section{FMR1}

Primers were designed in the (CGG)n flanking sequences of the FMR1 gene. ${ }^{14}$ Forward primer FMR1-P1 was 5' labelled (Fam) and the reverse primer FMR1-P2 was unlabelled. Primer sequences were FMR1-F: Fam 5'-GCT CAG CTC CGT TTC GGT TTC ACT TCC GGT-3', FMR1-R 5'-AGC CCC GCA CTT CCA CCA CCA GCT CCT CCA-3'.
PCR conditions were as follows: $1 \times \mathrm{PCR}$ buffer, $0.2 \mathrm{mmol} / 1$ dNTPs, $0.25 \mathrm{mmol} / 1$ 7-deaza-dGTP, $1.25 \mathrm{mmol} / \mathrm{l} \mathrm{Mg++}$, and $3 \mathrm{U}$ $\mathrm{Taq}$ (Gibco BRL) in a $50 \mu \mathrm{l}$ final volume. After initial denaturation for 10 minutes at $98^{\circ} \mathrm{C}$, a hold step at $70^{\circ} \mathrm{C}$ was performed during which the Taq was added to the samples, followed by one minute at $65^{\circ} \mathrm{C}$ and two minutes at $72^{\circ} \mathrm{C}$. Thirty cycles were then performed for one minute each at temperatures of $98^{\circ} \mathrm{C}, 63^{\circ} \mathrm{C}$, and $72^{\circ} \mathrm{C}$. A final elongation step was done for 10 minutes at $72^{\circ} \mathrm{C}$.

For both $A R$ and FMR 1 targeted assays, $1 \mu \mathrm{l}$ of the PCR product was resuspended in $12 \mu \mathrm{l}$ of TSR (Applied Biosystems). Samples were loaded on POP4 polymer on an automated ABI310 supplied with Genescan analysis software.

Controls

Inactivation studies were also performed with lymphocyte DNA from unrelated normal females as negative controls and XNP/ATR-X carrier women known to have a totally skewed pattern of XCI as positive controls.

SEQUENCING

The MECP2 gene was sequenced for each patient using genomic DNA as a template and also using cDNA for the patients for whom a lymphoblastoid cell line was available. Primer sequences for both genomic DNA and cDNA are available upon request. The PCR samples were directly sequenced, after purification with Qiagen PCR purification kit, using a LiCor sequencer and M13 tailed primers.

NORTHERN BLOTTING

Lymphocyte polyA+ RNA was prepared using Qiagen direct mRNA kit. One $\mu \mathrm{g}$ of RNA was loaded onto a $0.8 \%$ agarose $3 \%$ formaldehyde gel, and electrophoresis was conducted in $1 \times$ borate buffer for six hours at 50 volts. The gel was transferred to HybondN+ membranes (Amersham) according to the manufacturer's instructions. Hybridisation was carried out in $50 \%$ formamide buffer at $42^{\circ} \mathrm{C}$ for 16 hours. A 800 bp $M E C P 2$ cDNA probe derived from the coding region of exon 3 was used to probe the northern blot.

RT-PCR EXPERIMENTS

Total RNA was extracted from lymphoblastoid cell lines using standard procedures. ${ }^{15}$ PolyA+ RNA was then prepared using the total RNA as a template using the Qiagen RNeasy kit (Qiagen) according to the manufacturer's instructions. The RNA sample was treated with RQ1 DNase for 15 minutes at $37^{\circ} \mathrm{C}$ and precipitated using standard procedures. One $\mu \mathrm{g}$ of polyA+ RNA was reverse transcribed in 50 $\mu 1$ of $1 \times$ SuperScript reaction buffer (Gibco BRL) containing $3 \mathrm{ng} / \mu \mathrm{l}$ of dN6 oligonucleotides, 40 units of RNasin (Promega), $1 \mathrm{mmol} / 1$ dNTP, and 200 units of SuperScript II reverse transcriptase (Gibco BRL) for one hour at $42^{\circ} \mathrm{C} ; 1 / 10$ th of this reaction mixture was subsequently used for PCR amplification. 
Family 1

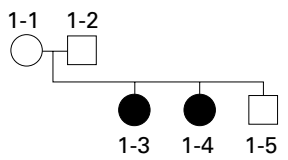

Family 3

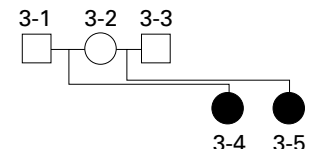

Family 5

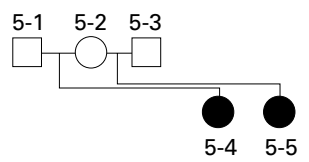

Figure 1 Pedigree of the five familial cases of Rett syndrome.

GENOTYPING

The DXS markers used in this study are based on the Genethon human genetic linkage map. One primer for each PCR primer pair was labelled with the IRD800 infrared dye. PCR reactions were done in $50 \mu \mathrm{l}$ volume for 30 cycles consisting of 45 seconds denaturation at $94^{\circ} \mathrm{C}, 45$ seconds annealing at $55^{\circ} \mathrm{C}$, and 45 seconds extension at $72^{\circ} \mathrm{C}$. PCR products were directly loaded onto a LiCor automated sequencer to determine the allele sizes.

\section{Results}

FOUR FAMILIAL RTT CASES DID NOT HAVE

MUTATIONS IN THE CODING REGION OF MECP2

We have studied five RTT families (fig 1) segregating a typical Rett phenotype fulfilling the international criteria for RTT diagnosis. We have screened these families for the presence of mutations in the coding region of the MECP2 gene using SSCP, direct sequencing of genomic DNA, and RT-PCR experiments using lymphocyte RNA as a template. RT-PCR products were normal in both size and abundance (data not shown), indicating that probably no mutation affecting either the splicing or stability of the mRNA was present in the families studied.

SSCP experiments and direct sequencing of genomic DNA did not show a mutation in the coding region of the $M E C P 2$ gene in four families out of five. A missense mutation (C to $\mathrm{T}$ nucleotide change resulting in R106W) was found in one family (family 5) in the two half sisters but not in their mother. The presence of this mutation has been confirmed by restriction analysis of genomic DNA (data not shown) and was shown to be absent from 100 unrelated X chromosomes.

A TOTALLY SKEWED PATTERN OF XCI SEGREGATES IN THE RTT FAMILIES WITHOUT MECP2 MUTATION In order to assess the XCI patterns in the four RTT families without $M E C P 2$ mutation, we used a polymorphism at the androgen receptor locus, and assayed methylation of the different alleles by digestion of the DNA with a methylation sensitive enzyme (HpaII) (fig 2). As positive controls, we used DNA samples from female carriers of the ATR-X syndrome since we have shown that a totally skewed pattern of XCI is caused by the presence of a mutation in the gene involved in this disorder. ${ }^{16}$

All the tested mothers (four out of four) had a totally skewed XCI pattern. In addition, six out of eight affected girls in the same families also have a totally skewed XCI pattern (the two affected girls not scored as totally skewed are 1-3 who displays a random XCI and 4-3 who is homozygous at the $A R$ and FMR1 loci). In each case, we have scored the degree of skewing to $>95: 5$ since no second allele was detected after amplification of HpaII digested genomic DNA on heterozygous samples (fig 2). Since lymphoblastoid cell lines were the only material available to perform this analysis, we postulated that our data could be the result of
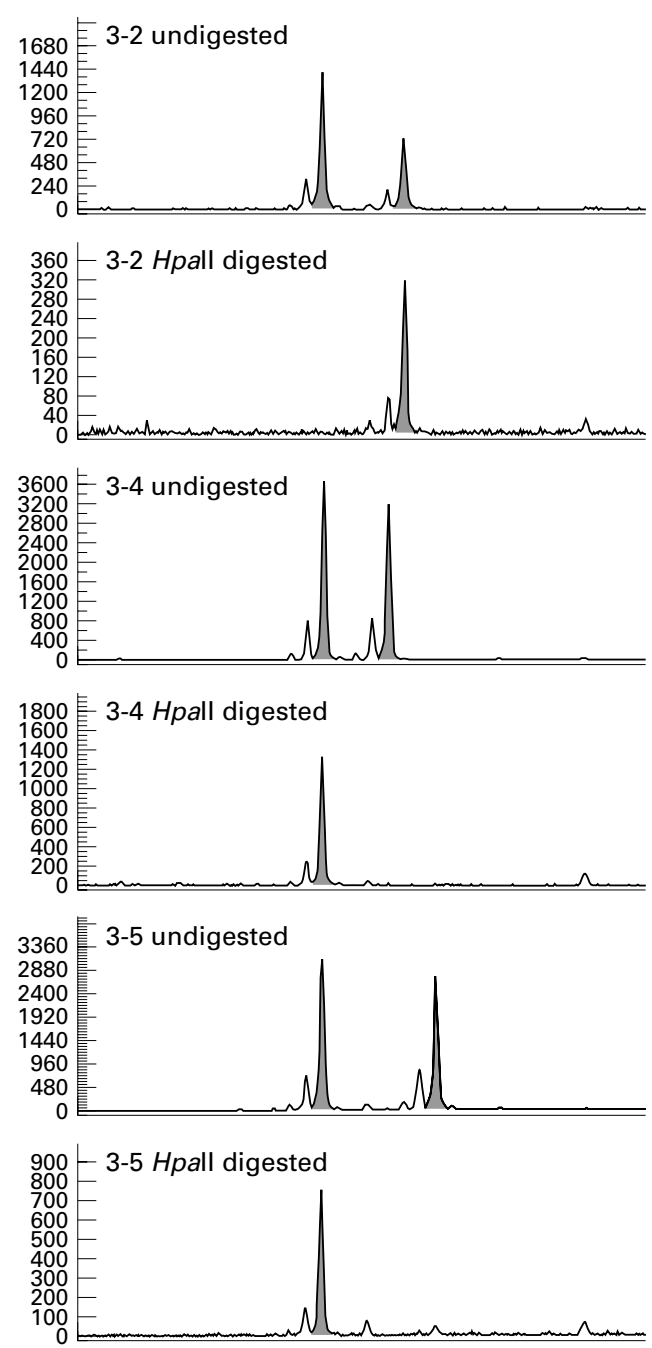

Figure 2 Transmission of the totally skewed XCI pattern in family 3. Numbering of subjects is the same as in fig 1. A totally skewed XCI pattern is observed both in the mother and her affected daughters after digestion with the methylation sensitive restriction endonuclease HpaII. The patient's active chromosome is of paternal origin in both cases while the maternally inherited chromosome is totally inactivated. 
Table 1 Summary of the X chromosome inactivation tests performed on RTT mothers and their daughters (for the four familial cases without MECP2 mutation reported in this study), CEPH controls, sporadic cases of RTT, and ATR-X carrier females. Females were scored as "skewed" when the ratio of XCI was above 95:5

\begin{tabular}{lclccc}
\hline & $\begin{array}{c}\text { Number } \\
\text { tested }\end{array}$ & Skewed & Not skewed & $\%$ skewed & $\begin{array}{l}\text { Mother to danghter } \\
\text { transmission (\%) }\end{array}$ \\
\hline RTT mothers & 4 & 4 & 0 & 100 & \\
RTT daughters & 8 & 6 & 2 & 75 & 100 \\
CEPH controls & 52 & 5 & 47 & 10 & 1 \\
RTT sporadic & 43 & 4 & 39 & 9 & 1 \\
ATR-X & 7 & 7 & 0 & 100 & \\
\hline
\end{tabular}

either the high proliferative status of lymphocytes or the transformation by EBV subsequently introducing an artefact into the results obtained. In order to rule out this possibility, which has been mentioned by other groups, ${ }^{8}$ we analysed the XCI pattern of 43 cases of sporadic RTT females. We decided to apply the same criteria as applied to familial studies and thus only skewed XCI with a ratio higher than 95:5 was scored as positive (that is, highly skewed). We found that $9 \%$ of RTT sporadic cases have a highly skewed XCI (table 1). In a next step, we analysed the XCI patterns of the mothers of the sporadic RTT females displaying a highly skewed XCI pattern. All the mothers displayed a random pattern of XCI, thus indicating that the skewed XCI is not transmitted from mothers to daughters and that it is thus probably not of genetic origin. In order to strengthen these results, we extended our analysis using lymphoblastoid cell lines from $52 \mathrm{CEPH}$ families. We determined the XCI patterns of one female in each family. We found a skewed XCI pattern in 10\% of females (as in the studied population of sporadic RTT cases). However, the skewed XCI pattern was transmitted from a mother to her daughters in one family among the 52 analysed. In our four RTT families without $M E C P 2$ mutation, the highly skewed pattern of XCI is segregating as a dominant genetic trait. A summary of the $\mathrm{X}$ chromosome inactivation analysis that we have performed is presented in table 1 . In addition, we have tested the XCI pattern in the familial case in which we identified a mutation in the MECP2 gene (family 5) and we found that the mother had a random XCI pattern (data not shown).

A CONTROLLING LOCUS FOR THE PRESENCE OF A SKEWED XCI PATTERN IS POTENTIALLY LOCATED ON THE PROXIMAL SHORT ARM OF THE X CHROMOSOME

To test if the skewed pattern of XCI observed in our four families is of genetic origin, we genotyped the whole $\mathrm{X}$ chromosome for each person using 32 polymorphic markers. For this analysis, we considered the skewed XCI pattern as being the "trait" and not the RTT phenotype. The results of this analysis are presented in fig 3. Exclusion mapping shows that almost all of the $\mathrm{X}$ chromosome can be excluded, excepted a region on the proximal short arm (Xp11.2-p11.4). This region has a genetic size of about $30 \mathrm{cM}$ and a physical size of about $15 \mathrm{Mb}$ based on the $\mathrm{X}$ chromosome

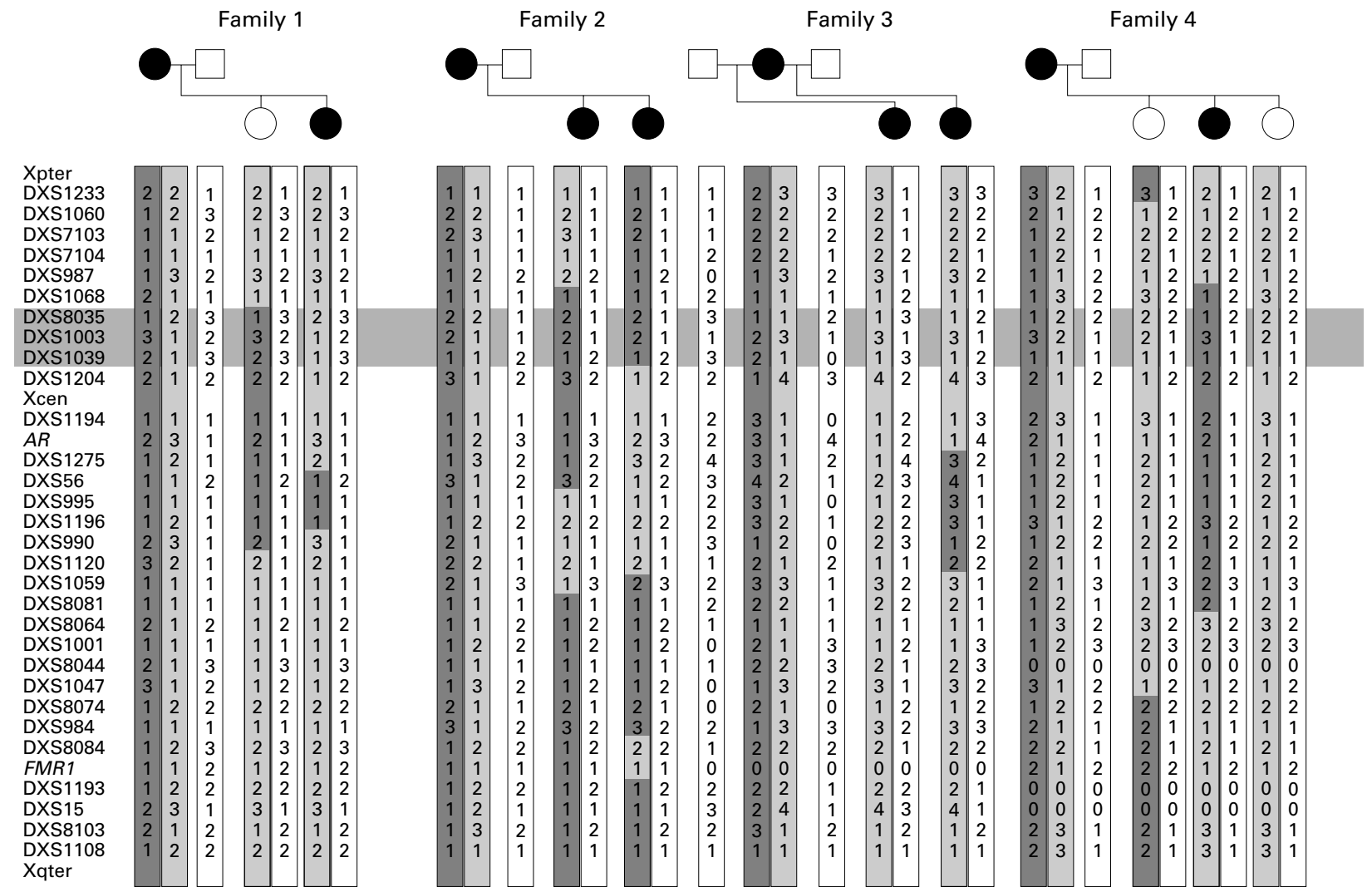

Figure 3 X chromosome haplotypes obtained for informative subjects in the four families without MECP2 mutation. The healthy brother of the RTT patients in family 1 was not genotyped. Each parental chromosome is shaded with a different grey in order to show more clearly the recombinant chromosomes in the offspring. The pedigree representation was changed so that the trait (represented by black symbols) is the totally skewed XCI pattern. The critical region potentially containing the locus responsible for the skewing of XCI is located between DXS1068 and DXS1204 (horizontally shaded area). 


\begin{tabular}{|c|c|c|c|c|c|c|c|c|c|c|c|c|c|c|c|c|}
\hline & \multicolumn{3}{|c|}{ Family 1} & \multicolumn{4}{|c|}{ Family 2} & & \multicolumn{4}{|c|}{ Family 3} & \multicolumn{4}{|c|}{ Family 4} \\
\hline$A R$ & 2(3) 1 & 21 & 3 (1) & (1) 2 & 3 & $1(3)$ & 2 (3) & 2 & 3 (1) & 4 & $1(2)$ & 1 (4) & (2) 1 & 1 & 11 & 2(1) 11 \\
\hline DXS8084 & 123 & 23 & 23 & 12 & 2 & 12 & 22 & 1 & 22 & 2 & 21 & 22 & 22 & 1 & 21 & $\begin{array}{llll}2 & 1 & 2 & 1\end{array}$ \\
\hline FMR1 & $\begin{array}{lll}112 & 2\end{array}$ & 12 & $1(2)$ & 11 & 1 & 11 & 11 & 0 & 00 & 0 & 00 & 00 & (2) 1 & 2 & 22 & 1(2) 12 \\
\hline $\begin{array}{l}\text { DXS1193 } \\
\text { DXS15 } \\
\text { DXS8103 } \\
\text { DXS108 }\end{array}$ & $\begin{array}{lll}1 & 2 & 2 \\
2 & 3 & 1 \\
2 & 1 & 2 \\
1 & 2 & 2\end{array}$ & $\begin{array}{ll}2 & 2 \\
3 & 1 \\
1 & 2 \\
2 & 2\end{array}$ & $\begin{array}{ll}2 & 2 \\
3 & 1 \\
1 & 2 \\
2 & 2\end{array}$ & $\begin{array}{ll}1 & 2 \\
1 & 2 \\
1 & 3 \\
1 & 1\end{array}$ & $\begin{array}{l}2 \\
1 \\
2 \\
1\end{array}$ & $\begin{array}{ll}1 & 2 \\
1 & 1 \\
1 & 2 \\
1 & 1\end{array}$ & $\begin{array}{ll}1 & 2 \\
1 & 1 \\
1 & 2 \\
1 & 1\end{array}$ & $\begin{array}{l}2 \\
3 \\
2 \\
1\end{array}$ & $\begin{array}{ll}2 & 2 \\
2 & 4 \\
3 & 1 \\
1 & 1\end{array}$ & $\begin{array}{l}1 \\
1 \\
2 \\
1\end{array}$ & $\begin{array}{ll}2 & 2 \\
4 & 3 \\
1 & 2 \\
1 & 1\end{array}$ & $\begin{array}{ll}2 & 1 \\
4 & 1 \\
1 & 2 \\
1 & 1\end{array}$ & $\begin{array}{ll}0 & 0 \\
0 & 0 \\
2 & 3 \\
2 & 3\end{array}$ & $\begin{array}{l}0 \\
0 \\
1 \\
1\end{array}$ & $\begin{array}{ll}0 & 0 \\
0 & 0 \\
2 & 1 \\
2 & 1\end{array}$ & $\begin{array}{llll}0 & 0 & 0 & 0 \\
0 & 0 & 0 & 0 \\
3 & 1 & 3 & 1 \\
3 & 1 & 3 & 1\end{array}$ \\
\hline
\end{tabular}

Figure 4 Parental origin of the active and inactive X chromosomes in the four Rett families studied for XCI. The androgen receptor (AR) alleles of each chromosome are indicated below each pedigree member. Circled AR alleles indicate a total bias in XCI resulting in 100\% activity of the chromosome carrying this allele. The same representation is used for FMR1 alleles. Genotypes in Xq28 are indicated below FMR1 and the phase has been set between AR and Xq28 markers for each chromosome. Since the FMR1 locus was not informative in family 2, we were unable to determine its inactivation status.

genetic and physical maps, respectively. Multipoint linkage analysis was also performed using these data and a lod score of 1.5 was obtained with the same region of the $\mathrm{X}$ chromosome (data not shown). Additional similar familial RTT cases need to be added to the analysis in order to reach significance. We have haplotyped with the same markers the $\mathrm{CEPH}$ family in which we found that a skewed $\mathrm{XCI}$ pattern is transmitted from the mother to four of her five daughters, but the Xp11.2$\mathrm{Xp} 11.4$ region was excluded by this analysis (data not shown).

IT IS ALWAYS THE PATERNALLY INHERITED $\mathrm{X}$ CHROMOSOME WHICH IS ACTIVE IN THE RTT GIRLS PRESENTING A TOTALLY SKEWED PATTERN OF XCI

The X chromosome haplotypes obtained in the previous step (see above) were used in order to determine the parental origin of the active $\mathrm{X}$ chromosome. In all informative girls with a totally skewed XCI pattern (six out of eight), it is the paternally inherited $\mathrm{X}$ chromosome which is active, the maternally inherited $\mathrm{X}$ chromosome being completely inactive (fig 4).
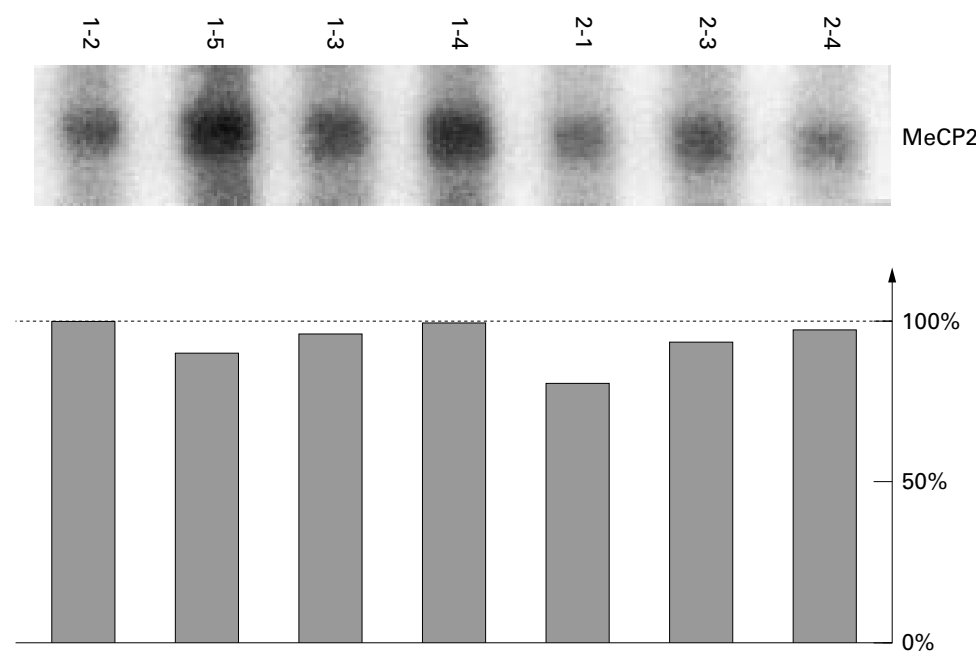

Normalised MeCP2 expression

Figure 5 Analysis of MECP2 expression after northern blotting. Poly $A+R N A$ for each subject from two families (labelled as in fig 1) was hybridised with an MECP2 cDNA probe. (Top) MECP2 $1.8 \mathrm{~kb}$ transcript expression. (Bottom) Quantification of MECP2 expression after analysis with a phosphoimager and correction of the MECP2 expression based on ribosomal RNA abundance (subject 1-2 was arbitrarily given a value of $100 \%$ for MECP2 expression); no variation larger than $20 \%$ was observed for $M E C P 2$ expression in these two families.
Using the inactivation status at FMR1, the polymorphism of this locus, and the $\mathrm{X}$ chromosome haplotypes, we show that in families 1,2 , and 3 it is probably the same Xq27.3q28 haplotype which is active in the mother and inactive in the affected girls who display a totally skewed XCI pattern. Concerning the haplotype associated with RTT, since the grandparents' DNA is not available for these families, and since all affected girls are obligate carriers of their father's haplotype, we cannot track which chromosome is carrying the Rett mutation. However, in family 3 , it is very likely that it is a maternal chromosome that carries the RTT mutation since each patient has a different father.

ANALYSIS OF MECP2 EXPRESSION

One explanation for the fact that $20-30 \%$ of the RTT sporadic cases do not have a mutation in the coding sequence of $M E C P 2$ could be that other mutations affecting either the expression or the stability of the transcript are present in these subjects. In order to test this hypothesis, we performed northern blot analysis to quantitate $M E C P 2$ expression in the RTT families for whom cell lines were available. Normal males or females from the same families were also included in the analysis as controls. The results of this analysis are shown in fig 5 . The amount of $M E C P 2$ transcript in the affected girls is almost identical (maximal observed variation of $20 \%$ after quantification using phosphoimaging) to the amount present in control samples, thus probably ruling out the existence of a mutation affecting the expression of the gene or the stability of the transcript. However, a mutation which affected specifically the stability of the large $M E C P 2$ transcripts ( $5 \mathrm{~kb}$ and $10 \mathrm{~kb}$ ) would have been missed in our experiments since these two transcripts are poorly expressed in lymphocytes. The same experiments would need to be carried out using biological samples where the expression of these transcripts is high (for example, brain), which was impossible to perform in our families.

Another explanation for our results would be that the RTT phenotype in our four families without $M E C P 2$ mutation could be the result of a gene abnormally escaping inactivation (see Discussion) and this gene could be MECP2. Since the analysis of steady state mRNA levels 


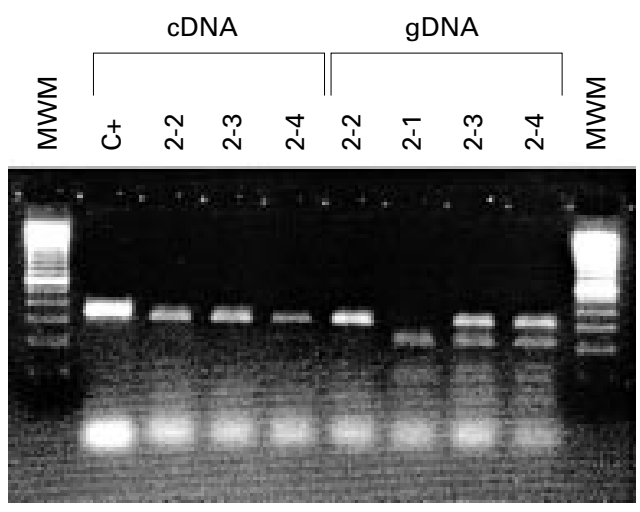

Figure 6 Analysis of $M E C P 2$ expression in family 2 using RT-PCR. Results of the restriction analysis of a 358 bp PCR product containing the polymorphism identified in the 3' UTR of MECP2. PCR products obtained from cDNA (left) or genomic DNA (gDNA, right) were digested with the BstNI restriction endonuclease. The wild type sequence contains four BstNI sites. The polymorphism identified in this family suppresses one BstNI site. The paternal allele is the only allele expressed by the affected $R T T$ patients in this family. $M W M=$ molecular weight marker. $C+=$ undigested $P C R$ product (there is a $40 \mathrm{bp}$ difference between the undigested PCR product and the higher band after BstNI digestion).

using northern blotting can be tricky (especially if the dosage difference is $1 v 2$ ), we looked for a polymorphism in the 3 ' untranslated region of $M E C P 2$, in order to determine the expression level of both alleles. We did indeed find a polymorphism in the $M E C P 2$ transcript after sequencing part of the 3' UTR in the two affected patients in family 2 (G2356C, numbered according to GenBank entry AJ132917). Analysis of genomic DNA indicated that the "variant" allele was inherited from the father, the other being inherited from the mother (fig 6). The fact that the father is the carrier of the "variant" allele shows that the nucleotide change found in the 3' UTR of MECP2 is not disease causing. RT-PCR analysis using PCR primers flanking this polymorphism shows that the father expresses the "variant" $M E C P 2$ allele (as expected) and that his two daughters are both expressing the same (paternal) MECP2 allele. No maternal allele was detected, consistent with the observation that both sisters have a completely skewed XCI pattern. This experiment shows that MECP2 expression is monoallelic in this family, and that the RTT phenotype cannot be the result of a mutation causing MECP2 to escape inactivation.

\section{Discussion}

Our data show that a totally skewed XCI pattern segregates in the four RTT families that we have analysed. Strikingly, this skewed pattern does not affect the same $\mathrm{X}$ chromosome in mothers and in affected girls (since it is the paternally inherited X chromosome which is active in RTT girls). An analysis performed in normal subjects has shown that an extremely skewed XCI pattern can be found in females without any disease phenotype. ${ }^{17}$ In our hands, about $10 \%$ of the female lymphoblastoid cell lines (CEPH families or sporadic RTT cases) display a highly skewed XCI pattern. This can be because of either the high rate of proliferation of the lymphocytes or EBV transformation. However, this trait is not frequently transmitted through generations (one case out of 95 analysed in the present study), and is thus probably not of genetic origin. Hence, the segregation of a totally skewed XCI pattern in the four RTT families analysed in this study is probably not the result of chance, but rather an unknown biological factor. The fact that this trait segregates in our familial RTT cases strongly argues in favour of the transmission of a genetic trait. Two possible explanations for the presence of a skewed XCI pattern have been proposed. The first ("primary cause") is probably linked to the mechanism of $\mathrm{X}$ chromosome inactivation in itself. This phenomenon has been observed in several families. ${ }^{18-20}$ In one case,${ }^{18}$ it was linked to a mutant XIST allele. The second proposed mechanism is the selection against a deleterious allele during embryogenesis or cell differentiation. This is the case for several severe $\mathrm{X}$ linked disorders. ${ }^{21}{ }^{22}$ In our study, the latter mechanism seems very unlikely for several reasons. First, it is always the chromosome carrying the mutation which is inactivated in carrier mothers of deleterious X linked traits and only males are affected, which is not the case in our RTT families. In addition, one would expect the Rett chromosome to be inactive in affected girls if a counterselection occurs against the deleterious allele. Thus, the first mechanism seems to be the most likely, as there is no need for the skewed pattern to be associated with a deleterious allele to be transmitted. However, when a skewed XCI pattern was identified, it seemed to affect the same $\mathrm{X}$ chromosome through generations and not to act randomly on maternal or paternal X chromosomes, as we observed in our families. At this stage of the work, it is difficult to explain the "inversion" of the skewed XCI pattern observed for the chromosome transmitted from mothers to daughters in our families.

If the totally skewed XCI pattern is a genetic trait segregating in these four RTT families, it should be possible to localise it by classical linkage analysis. Using 32 polymorphic markers distributed evenly along the human $\mathrm{X}$ chromosome for genotyping, we have excluded almost all regions of the $\mathrm{X}$ (including $\mathrm{Xq} 28$ and $\mathrm{Xq13}$ ) from being the region in which a locus causing a completely skewed XCI pattern could be located. This shows that the two traits (that is, Rett syndrome and the completely skewed XCI pattern) are not linked, since the $\mathrm{Xp} 11$ region is excluded from involvement in the Rett syndrome phenotype based on allele sharing by affected girls in this region of the $\mathrm{X}$ chromosome. It also excludes a mutated allele of XIST as being the cause of this completely skewed XCI pattern. However, a $30 \mathrm{cM}$ region located between markers DXS1068 and DXS1204 systematically segregates with the skewed pattern of inactivation in our families and thus cannot be excluded. This region of approximately $15 \mathrm{Mb}$ is a potential candidate region to contain a gene acting on X chromosome inactivation. Unfortunately, the lod score obtained using our data is not significant $(Z=1.5$ at $\theta=0)$ and more families need to be studied.

It had been proposed that the Rett locus could be inactivated in the mothers and active 


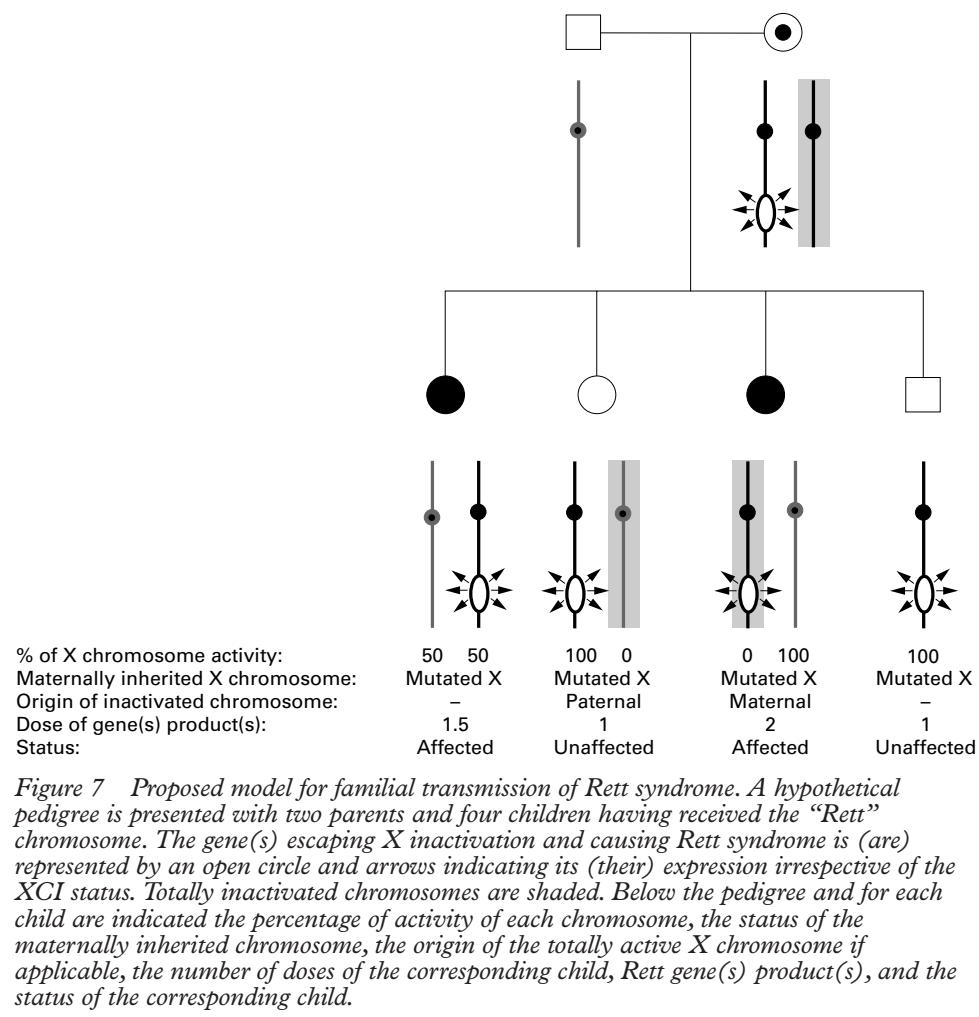

in their affected daughters. ${ }^{6}$ Our data rule out this hypothesis since it is the paternally inherited X chromosome that was found to be active in the affected daughters. In family 3 , it is likely that the mother is carrying the RTT chromosome since the affected daughters have different fathers.

Our data lead us to propose a model in which the RTT mutation allows normally inactivated gene(s) to escape $\mathrm{X}$ inactivation. In the mothers, the chromosome carrying the RTT mutation is active, while the normal $\mathrm{X}$ is inactive leading to only one dose of the RTT gene(s) being expressed. In the affected daughters, the RTT chromosome is inactivated, but the mutant RTT gene(s) which escape(s) X inactivation remain(s) expressed. Since the paternal $\mathrm{X}$ chromosome is active, RTT affected girls will have two doses of the RTT gene(s) expressed (this mechanism is summarised in fig 7). According to this model, Rett syndrome would become familial when a mutation causing the RTT gene(s) to escape X inactivation occurs in a family in which a totally skewed pattern of $\mathrm{X}$ inactivation segregates, allowing the RTT mutation to be inherited. This hypothesis is compatible with the hypothesis of Thomas, ${ }^{3}$ stating that the RTT mutation originates from the father. A male specific germline mutation originating from the father or grandfather, which allows an $\mathrm{X}$ linked gene to escape inactivation, could thus be involved in sporadic (father's germline mutation) and familial (grandfather's germline mutation) forms of the disorder not resulting from $M E C P 2$ mutations.

The MECP2 gene is involved in the control of gene expression through the binding of the corresponding protein to methylated $\mathrm{CpG}$ dinucleotides. ${ }^{23}$ These findings are of major interest since methylation is also a mechanism involved in $\mathrm{X}$ inactivation. According to our model, an alternative explanation is that the gene which escapes inactivation in our Rett families is $M E C P 2$. Unfortunately, $M E C P 2$ expression is the same in Rett girls as in their unaffected relatives based on northern blot quantification of $M E C P 2 \mathrm{RNA}$. In addition, we tested the hypothesis of biallelic expression of $M E C P 2$ in a family in whom we identified a polymorphism in the 3 ' untranslated region of the gene. Only the paternal allele is expressed in his two affected daughters, ruling out that $M E C P 2$ escapes inactivation in this family.

A possibility that should be mentioned is that we may have missed an unknown phenomenon which could affect $M E C P 2$, since lymphocytes were the only cells that we studied. A second hypothesis is that the molecular causes of Rett syndrome are diverse and thus it could be a genetically heterogeneous syndrome. In order to gain more information and to answer these questions, we are currently testing expression of the known genes in the linkage area, to detect a potential deregulation of one of them.

The first two authors contributed equally to this work. We would like to thank our colleagues and clinicians for providing the clinical material. We thank M J Mitchell, M G Mattéi, and F Muscatelli for helpful comments and discussions. We are grateful to Caroline Lacoste for excellent technical assistance. We thank Howard Cann for providing the CEPH families' DNA used in this study. This work was supported by the Association Française du Syndrome de Rett, Association Française contre and Margaret Axson Johnson Foundation, and the INSERM progress network.

1 Armstrong DD. Review of Rett syndrome. f Neuropathol Exp Neurol 1997;56:843-9.

2 Hagberg B, Aicardi J, Dias K, Ramos O. A progressive syndrome of autism, dementia, ataxia, and loss of purposeful hand use in girls: Rett's syndrome: report of 35 cases. Ann Neurol 1983;14:471-9.

3 Thomas GH. High male:female ratio of germ-line mutations: an alternative explanation for postulated gestational lethality in males in X-linked dominant disorders. Am f Hum Genet 1996;58:1364-8.

4 Webb T, Clarke A, Hanefeld F, Pereira JL, Rosenbloom L, Woods CG. Linkage analysis in Rett syndrome families suggests that there may be a critical region at Xq28. F Med Genet 1998;35:997-1003.

5 Xiang F, Zhang Z, Clarke A, Joseluiz P, Sakkubai N, Sarojini B, Delozier-Blanchet CD, Hansmann I, Edstrom L, Anvret B, Delozier-Blanchet CD, Hansmann I, Edstrom L, Anvret
M. Chromosome mapping of Rett syndrome: a likely candidate region on the telomere of Xq. $\mathcal{F}$ Med Genet 1998;35: didate regior $297-300$.

6 Sirianni N, Naidu S, Pereira J, Pillotto RF, Hoffman EP. Rett syndrome: confirmation of X-linked dominant inheritance, and localization of the gene to Xq28. Am f Hum Genet 1998;63:1552-8.

7 Amir RE, Van den Veyver IB, Wan M, Tran CQ, Francke U, Zoghbi HY. Rett syndrome is caused by mutations in $\mathrm{X}$-linked $M E C P 2$, encoding methyl-CpG binding protein 2. Nat Genet 1999;23:185-8.

8 Wan M, Lee SS, Zhang X, Houwink-Manville I, Song HR, Amir RE, Budden S, Naidu S, Pereira JL, Lo IF, Zoghbi HY, Schanen NC, Francke U. Rett syndrome and beyond: recurrent spontaneous and familial $M E C P 2$ mutations at CpG hotspots. Am f Hum Genet 1999;65:1520-9.

9 Van den Veyver IB, Zoghbi HY. Methyl-CpG-binding protein 2 mutations in Rett syndrome. Curr Opin Genet Dev 2000;10:275-9.

10 Hagberg B, Aicardi J, Dias K, Ramos O. A progressive syndrome of autism, dementia, ataxia, and loss of purposeful hand use in girls: Rett's syndrome: report of 35 cases. Ann Neurol 1983;14:471-9.

11 Haenggeli CA, Moura-Serra J, DeLozier-Blanchet CD. Two sisters with Rett syndrome. F Autism Dev Disord 1990;20: 129-38.

12 Ellison KA, Fill CP, Terwilliger J, DeGennaro LJ, Martin-Gallardo A, Anvret M, Percy AK, Ott J, Zoghbi H. Examination of X chromosome markers in Rett syndrome: exclusion mapping with a novel variation on multilocus linkage analysis. Am f Hum Genet 1992;50:278-87.

13 Allen RC, Zoghbi HY, Moseley AB, Rosenblatt HM, Belmont JW. Methylation of HpaII and HhaI sites near the polymorphic CAG repeat in the human androgen-receptor polymorphic CAG repeat in the human androgen-receptor
gene correlates with $\mathrm{X}$ chromosome inactivation. $A m \mathcal{F}$ Hum Genet 1992;51:1229-39. 
14 Carrel L, Willard HF. An assay for X-inactivation based on differential methylation at the fragile X locus, FMR1. Am $\mathcal{F}$ differential methylation at

15 Chomczynski P, Sacchi N. Single-step method of RNA isolation by acid guanidinium thiocyanate-pheno-chloroform extraction. Anal Biochem 1987;162:156-9.

16 Lossi AM, Millan JM, Villard L, Orellana C, Cardoso C, Prieto F, Fontes M, Martinez F. Mutation of the XNP/ATR-X gene in a family with severe mental retardation, spastic paraplegia and skewed pattern of $\mathrm{X}$-inactivation: demonstration that the mutation is involved in the inactivation bias. Am f Hum Genet 1999;65:558-62.

17 Naumova AK, Olien L, Bird LM, Smith M, Verner AE, Leppert M, Morgan K, Sapienza C. Genetic mapping of $\mathrm{X}$-linked loci involved in skewing of X chromosome inactivation in the human. Eur f Hum Genet 1998;6:552-62.

18 Plenge RM, Hendrich BD, Schwartz C, Arena JF, Naumova A, Sapienza C, Winter RM, Willard HF. A promoter mutaA, Sapienza C, Winter RM, Willard HF. A promoter mutaX chromosome inactivation. Nat Genet 1997;17:353-6.
19 Naumova AK, Plenge RM, Bird LM, Leppert M, Morgan $\mathrm{K}$, Willard HF, Sapienza C. Heritability of X chromosome inactivation phenotype in a large family. Am f Hum Genet

20 Pegoraro E, Whitaker J, Mowery-Rushton P, Surti U, Lanasa M, Hoffman EP. Familial skewed X-inactivation: a molecular trait associated with high spontaneous-abortion rate maps to Xq28. Am f Hum Genet 1997;61:160-70.

21 Vulliamy TJ, Knight SW, Dokal I, Mason PJ. Skewed $\mathrm{X}$-inactivation in carriers of X-linked dyskeratosis congenita. Blood 1997;90:2213-16.

22 Woffendin H, Jakins T, Jouet M, Stewart H, Landy S, Haan E, Harris A, Donnai D, Read A, Kenwrick S. $\mathrm{X}$-inactivation and marker studies in three families with incontinentia pigmenti: implications for counselling and gene localisation. Clin Genet 1999;55:55-60.

23 Lewis JD, Meehan RR, Henzel WJ, Maurer-Fogy I, Jeppesen P, Klein F, Bird A. Purification, sequence, and cellular localization of a novel chromosomal protein that binds to methylated DNA. Cell 1992;69:905-14.

\title{
1st Asia Pacific Forum on Quality Improvement in Health Care
}

\author{
Three day conference
}

\section{Wednesday 19 to Friday 21 September 2001 \\ Sydney, Australia}

We are delighted to announce this forthcoming conference in Sydney. Authors are invited to submit papers (call for papers closes on Friday 6 April), and delegate enquiries are welcome. The themes of the Forum are:

- Improving patient safety

- Leadership for improvement

- Consumers driving change

- Building capacity for change: measurement, education and human resources

- The context: incentives and barriers for change

- Improving health systems

- The evidence and scientific basis for quality improvement.

Presented to you by the BMJ Publishing Group (London, UK) and Institute for Healthcare Improvement (Boston, USA), with the support of the the Commonwealth Department of Health and Aged Care (Australia), Safety and Quality Council (Australia), NSW Health (Australia), and Ministry of Health (New Zealand).

For more information contact: quality@bma.org.uk or fax +44(0)20 73836869

\section{Narrative Based Medicine, An Interdisciplinary Conference}

\author{
Research, Narrative, and Practice
}

A two day conference-Monday 3rd and Tuesday 4th September 2001

$$
\text { Homerton College, Cambridge, UK }
$$

$$
\text { BMF Publishing Group }
$$

For full details contact: BMA/BMJ Conference Unit, Tavistock Square, London, WC1H 9JP Tel: +44 (0)20 7383 6819; fax: +44 (0)20 7383 6663; email: clyders@bma.org.uk. 